\title{
Constitutional Change in Federations: The Role of Complementary Institutions
}

\author{
Jenna Bednar \\ University of Michigan \\ and the Santa Fe Institute \\ jbednar@umich.edu
}

To appear in Arthur Benz and Jörg Broschek, eds., Federal

Dynamics: Continuity, Change, and the Varieties of

Federalism, Oxford University Press, forthcoming.

April 3, 2012

\begin{abstract}
This essay applies new developments in complex systems theory to understand how constitutional change can occur informally, without amendment. The chapter develops a three-part theory of constitutional dynamics by analyzing the the complex interaction of the federal system's varied building blocks: the national government, the state governments, and the auxiliary institutions of governance (such as a judiciary), and the non-governmental institutions, including the party system. First, constitutional innovation derives from constitutional ambiguity and institutional imperfection. Second, complementary institutions constrain informal constitutional change to an incremental path, preventing radical ruptures from past practice. Third, through a model of behavioral spillovers and cross-domain influences, the chapter offers a theory of the emergence of constitutional trends. These dynamics may help us to to understand how periods of centralization and decentralization emerge, even as the constitutional text remains constant.
\end{abstract}


The chaos of structure and function is matched by a chaos of political process (Grodzins 1966:6).

\section{The Problem, Premise, and Questions}

Change to the distribution of authority in federal systems is practically necessary but theoretically elusive. Federalism is a system of government that allocates authority between a national and subnational government in order to achieve common goals relating to economic growth, security, and representation. The federal system is defined by its essential political components (the states and the composition of the national government), the way that authority is distributed between these components, and a set of safeguards to uphold the distribution of authority. In many policy realms, the national and subnational governments share authority. If the distribution of authority is ignored - if states or national government can assume authorities at their own whim, or shirk responsibilities when it suits - then federalism is meaningless. The authority boundary matters, how it is drawn and defended, for the welfare of the union.

Given the importance of the distribution of authority, its appropriateness should not be assumed to be permanent; instead, as the political, economic, or security environment changes, an alteration to the distribution of authority might improve outcomes. For example, as the efficiencies of scale grow, such as through increasing external trade, the productivity of the union may improve with centralization. On the other hand, as the public grows increas- 
ingly dissatisfied with centrally-provided policies, either because of mismatch between the uniform policy and local preferences, or because the central government is unable to improve upon its policies, then decentralization may be in order. With decentralization, lower levels of government can tailor policy to suit local preferences. And when existing policy is inefficient, decentralization creates the policy laboratories that could lead to the discovery of improved policy approaches, to the benefit of the whole country.

Given the natural volatility in the policy environment, it is not a stretch to argue that a federation's longevity and productivity depends upon its ability to adapt its internal rules that dictate which level of government is responsible for what policy domains. And yet existing theory implies that federations are uniquely unable to adapt their rules. Scholars from Montesquieu to Madison (as Publius) to the modern theory of George Tsebelis (2002) have shown how institutions create veto players that block legislation. Tsebelis' work chronicles how as the number of veto players grows, policies become locked into the status quo. To Madison, this gridlock is the key to a federation's success, as it prevents either level of government from usurping authority from the other. But what if a federation needs those authority boundaries to change? It would seem that federalism's diversity of governments and institutional safeguards dooms it to become stagnant, trapped by the very safeguards designed to protect it.

In this essay I leverage recent advances in complexity science to suggest that federations may not be trapped after all, and in fact that their fractal, 
internally diverse nature provides an unusual source of constitutional change through reinterpretation. Somewhat paradoxically, or at least in contrast with the implications of the veto players theory, federalism-with its multiple agents - contributes to the process of change, and is more likely to be incremental, without discontinuities. By viewing the federation as a system, and by examining the effect of multiple imperfect safeguards acting simultaneously, constitutional change is not confined to the periodic reworking of amendments or revisions, but instead, is a continuous and dynamic process of constitutional reinterpretation. My goal is not to definitively resolve the question of constitutional change, but instead to give a view of constitutional change that is evolutionary, organic, and often unplanned.

One way to change federalism's boundaries - to alter the level of government responsible for revenues or expenditures, or primary responsibility for policies - is to change the constitutional text that enables that authority. Textual changes occur through a formal process of amendment. All constitutions contain within them language for their own modification. Most federations have fairly inflexible constitutions, requiring not only a supermajority, but incorporating state (subnational) government aggregations as well as population-based aggregations. The rate of constitutional amendment correlates negatively with the magnitude of the barriers to change (Elkins, Ginsberg, and Melton 2009). If demand for change is independent of the institutional process, then in societies governed by more restrictive amendment procedures, a different method of constitutional change is necessary if 
the constitution is to adapt and continue to promote social welfare.

The constitutional text is often sufficiently ambiguous that formal amendment is not necessary. Just as multiple phenotypes may be expressed from a common genotype with sufficient plasticity, the words of the constitution are subject to interpretation. As the interpretation changes, the effect of the words change. Therefore constitutional change can occur - and regularly does occur - through an informal process of reinterpretation of the meaning of the words and how they ought to be applied to particular situations. This essay applies new developments in the theory of complex adaptive systems to understand the microfoundations - at the level of individual incentives and behavior-how informal constitutional change occurs.

A federation's constitutional court is the most intuitive interpreter of the constitution, but it is hardly the only one. Many political actors can "interpret" the constitution, and do so daily. When a legislature - state or federalpasses a bill it asserts a claim that the statute is constitutional (Thayer 1893, Whittington 1999). When the bureaucracy interprets legislation in order to implement it, it presumes that its interpretation is constitutional (Eskridge and Ferejohn 2010). When the media opines about government behavior, it offers a perspective on legitimate - constitutional-government action. In each case, as political actors and quasi-political actors carry out their tasks, they interpret federalism's boundaries.

Constitutional change in democratic regimes is a deeper process than political actors interpreting constitutional text opportunistically. True con- 
stitutional change implies public acceptance (Friedman 2003, Kramer 2004). Certainly if the change is a formal amendment, it is straightforward to see how public agreement is necessary. But in democracies, informal change too ultimately must face public reckoning. The public has the capacity to reject alterations to federalism's boundaries. The public is an imperfect safeguard, but quite powerful.

Therefore, the moment of constitutional transition implies the realization of a new public expectation. To theorize about constitutional change, it is not sufficient to point out that constitutions are flexible. One must generate a theory of constitutional dynamics that can explain the microprocesses that lead to new public expectations about governmental conduct. A theory of constitutional dynamics in democratic federations must address three questions:

1. How do constitutional innovations happen?

2. How are constitutional changes constrained to be incremental?

3. How does constitutional change spread across domains to create a general trend of peripheralization or centralization?

First, change requires a new idea about how the constitution might be different. Sometimes the idea can remain abstract and still inspire the public, as with cries for greater liberty and limited government. But often to acquire public acceptance, the constitutional idea should be put to practice; 
successful experience creates confidence and acceptance, or conversely, alerts the public to unforeseen consequences, such as heightened border security, in the name of safety and order, infringing on privacy and liberty. Institutional imperfection opens a window for experimentation, and federalism, with the multiplicity of governments, multiplies the opportunities. Section ?? explains constitutional innovation in federal systems.

Second, not all experimentation is healthy for the polity. In particular, abrupt transformations can be destabilizing. Therefore, a theory of robust constitutional dynamics should include a mechanism for constraining innovations so that change is incremental. Too rapid policy shifts upset the compact between the public and their government by making the government appear to be unreliable. One only need think of the rioting in Greece and Spain where severe cuts to social welfare programs in the name of austerity may be sound fiscal policy, but comes at the price of shattering the public's vision of the government's role in their lives.

Third, constitutional change often becomes a dynamic trend. Historians of federations often refer to periods of "centralization" or "peripheralization", implying a change to the balance of power between the federal and state governments. These different eras imply a change to the nature of the federal constitutional boundaries. The periods are not identified on the basis of one changed clause alone; the interpretation of individual clauses are related to changed interpretations of other clauses. A theory of constitutional dynamics should ask what force links these clauses. In Section ??, I describe one 
possible explanation for the emergence of these trends, tied to an analytical model.

\section{Innovation}

The text of a constitution is subject to interpretation for a simple reason: few clauses are unambiguous. Interpretations naturally are tied to interests, and as long as the interests of those governed by the constitution are distinct, interpretations will vary (Michelman 2003, Balkin 2011, Koppelman 2012). Federal constitutions structure the allocation of authority between federal and state governments. Whenever this allocation is ambiguous (which is to say, in almost every instance), federal or state governments will be tempted to interpret the boundary defining their authority opportunistically.

The components of the federation include of course the various governmentsnational and state. But it also includes the auxiliary institutions of governance that at times have an opportunity to express a judgment about the constitutionality of governmental action, such as the judiciary, the political parties, the media, and the public. These components are inextricably intertwined and jointly affect the distribution of authority; to study any one's effect in isolation is to ignore the extent to which each is dependent on the others.

Constitutional boundaries are protected by safeguards, such as a judiciary, or structural safeguards that constrain legislatures and executives by 
fragmenting authority. These safeguards are imperfect: sometimes they make mistakes in judgment, or sometimes their own rules prevent involvement. Because of the imperfection of the safeguards, governmental agents - federal and state governments - have a window to act on their opportunistic urges. Therefore it is natural - unavoidable - to have some variation in the adherence to the distribution of authority (Bednar 2006). National and subnational governments will inevitably press against the boundaries as they pursue policies to serve their own interests, and the safeguards of federalism, themselves imperfect, will tolerate some minor crossing of the line. This pressing is useful, but in itself is not constitutional change.

Setting aside for a moment the question of constitutional change, let us consider why it might be useful for these different governmental agents to interpret the boundaries of authority opportunistically, attempting policies that might not be constitutional. This experimentation is implicitly an inquiry as to whether the line defining governmental authority is drawn correctly. The boundaries are written in order to harness the federal and state governments in service to the welfare of the federation's public. When the constitution says that the federal government may regulate commerce between the states, as nearly all federal constitutions do, it is with the intention of fostering a domestic common market and the welfare benefits that follow from it. The commerce clause implies that those things that are not understood to be commerce are not regulable by the federal legislature, unless otherwise provided. if the federal government expands its interpretation 
of the word "commerce" to include insurance, it expands the realm of policies it can prescribe, and policy domains it can enter.

This expansion of the interpretation of the word commerce is not hypothetical, but instead is the crux of the United States's attempt to reform its system of health care, an expansion of federal governmental responsibility into a realm where it was previously active only for portions of the popultion: the poor, the elderly, and veterans. The U.S. Congress is currently relying on a 1944 judicial interpretation that insurance is commerce ${ }^{1}$ and a depression-era judicial interpretation of the aggregate effects on the market prices of one person's actions and the consequential right of the government to force an individual to participate in the market. ${ }^{2}$ Armed with these two constitutional understandings, Congress was able to radically transform the U.S. health insurance industry by creating an individual mandate to acquire insurance. A clause originally written to facilitate free trade between the states became a source of leverage to transform health care in the United States.

While we do not yet know whether Congress's health care legislation will survive judicial scrutiny given the pending lawsuits, this policy is an act of experimentation. Until the legislation is struck, any aspects of it that have already taken effect provide evidence of the policy's effectiveness, giving the public an opportunity to learn. Pundits describe the unintended benefits of

\footnotetext{
${ }^{1}$ United States v. South-Eastern Underwriters, 322 U.S. 533 (1944).

${ }^{2}$ Wickard v. Filburn, 317 U.S. 111 (1942).
} 
Republican strategies during the 2012 presidential campaign season, as the public is now considering the importance to it of access to preventive care and contraception.

Experimentation is a useful way to explore the policy space, to determine whether any change to the distribution of authority might be welfareenhancing. And the more diverse the source of the experimentation, the more likely the system will encounter a modification that improves it. This insight was first articulated by evolutionary theorist R.A. Fisher, who noted that the "rate of increase in fitness of any organism at any time is equal to its genetic variance in fitness at that time" (1930). Known as Fisher's fundamental theorem, this insight suggests that improvements to the organism depend on genetic variation, nature's way of trying new ideas (Page 2010).

To see the intuition, consider the classic complex systems metaphor of problem-solving being akin to finding the highest peak in a mountain range. It is fairly simple to find the local peak, that is, the highest point of whatever mountain you happen to be on: you just climb until you are at the peak. From there, you can compare your mountain's height to neighboring peaks, and move to another if it is higher than your own. But what if your view of the highest mountain in the range is obstructed by other peaks surrounding you, so that you just can't see whether there is any improvement available, let alone in which direction to head in order to climb higher? As all mountain climbers know, it is very common to miss the highest peak from any one vantage point. To recognize the highest peak in the range, it is best to try 
many approaches from diverse directions. In this sense, diversity leads to adaptation.

The mountain-climbing metaphor, and the attendant science, can be fruitfully applied to political policy making. If public policy is an act of problemsolving, some solutions are better than others, and the better they are, the higher up the mountain we move. If we are to find new, improved solutions, if we are to move to the global maximum, then having a diversity of perspectives makes us far more likely to reach common improvement (Page 2007).

We are most used to political differences leading to stagnation, and as this essay described above, the science of veto players (Tsebelis 2002) establishes the relationship between the number of veto players in a system and the stability of policy. If change is needed, veto players obstruct it. All else equal, systems with more veto players will be less likely to adapt to new circumstances, and their welfare will suffer. Political difference, it would seem, is destructive to progress.

Federal unions are different from the typical system because the state governments have significant autonomy to set policy and the federal governments have proven adept at overcoming internal constraints to tug the allocation of authority in their own favor. When different ideas about policy improvement can be acted upon, it is akin to genetic mutation. Sometimes the result of these experiments improves outcomes in ways that others would like to mimic. 
Experimentation by the state and federal governments alone is not sufficient for constitutional change; settled law implies public acceptance. Again, one needs a theory of how law might become settled, and for this, we must go beyond what biology can offer. Selection is a complete theory for change, but in political systems, the selection mechanism is public choice.

The multiple safeguards, judicial, political, popular, structural, is each flawed, imperfectly stopping violations to federalism's boundaries. Their imperfection is necessary first step for constitutional change: it opens up the window for policy experimentation. Their diversity, their differences, means that what one safeguard tolerates, another may not - each may offer its own distinctive interpretation of federalism's boundaries. Their disagreementsfor example when the Court reviews legislation passed through Congress (and therefore not stopped by the structural safeguards) - creates public dialogue. This dialogue engages the public, becoming a sort of open process of deliberation, from which it is possible that a new consensus might emerge.

Through the interpretive lenses of the various political actors the public gets multiple interpretations of the meaning of the constitution. Sometimes these interpretations reinforce public expectations and sometimes they challenge them. Changes in expressed preference can come from new information. It is this dependence upon the public that serves to shape constitutional dynamics. 


\section{Incremental Change and Continuity}

While the last section suggested a mechanism for the introduction of constitutional adjustments, any theory of constitutional change must also contain a theory of continuity. Constitutions are sustained by public perceptions of their legitimacy and the extent to which they unify a community. If the constitution's interpretation is too erratic in meaning or effect, it quickly loses legitimacy. Therefore, in order to understand robust constitutional changechange that improves a constitution's effectiveness rather than ruptures itone must also be able to explain how change is constrained to be incremental.

The theory of continuity is an extension of the theory developed in the first section. Constitutional change is driven by diverse, self-interested agents tempted to push boundaries. If the safeguards - judicial, structural, political, and popular-were perfect mechanisms, then they would prevent these trangressions. Instead, these safeguards each have characteristics that cause them to tolerate transgressions or otherwise be unable to prevent them. It is this imperfection of the safeguards that creates the possibility of constitutional change through policy experimentation.

Each safeguard - the Court, the political parties, the various branches of government, aggregated - has its own sense of the appropriate interpretation of the constitution, and more importantly, its own threshold of what policies it will tolerate. That is, each safeguard has its own point at which it determines that policy (whether enacted or, in the case of structural safeguards, 
considered) is beyond constitutional limits. Safeguards do not immediately arrest policy that it determines to be in excess of the constitution. Each safeguard is imperfect - its judgments may be flawed - and so to reduce the negative effects of costly errors, it tolerates some small deviances from what it considers to be constitutional practice.

While safeguards are inaccurate, prone to error, particularly for subtle discrepancies from constitutional practice, they grow increasingly accurate at recognizing and deterring transgressions as the transgressions grow more blatant. Policies are not simply "constitutional" or "unconstitutional"; very rarely is their constitutional status so crisply definable. Instead, constitutional clauses are subject to interpretation, and policies are complex and multidimensional, and so they can be more or less in line with constitutionality.

An important source of the system's accuracy for grosser violations is safeguard complementarity. Where one safeguard might miss an opportunity to catch a transgression, another, chronologically later to interact with the policy, can redirect it. For example, the No Child Left Behind Act (2001) represents a new degree of federal government involvement in setting education policy, a domain traditionally left to the states and local governments. This policy was President George W. Bush's signature domestic advance, and at the time of passage enjoyed overwhelming bipartisan support. Two safeguards that could have derailed the bill would appear to have missed the chance to respond: the political safeguards that emerge from the party 
system (given that the Republicans championed it, despite criticism from Republicans in state governments) and the structural safeguards, as the legislation passed both houses of Congress.

However, this read of the bill's history is not entirely correct. The original bill was far more centralizing. With resistance from the state Republicans, coupled with state involvement in reshaping the bill in Congress, the bill emerged looking far different from what President Bush and his team at the Department of Education envisaged. ${ }^{3}$ Rather than introducing a coherent set of national educational attainment standards, accountability measures, and a single timeline toward the goal of every child's educational success, much control of the program was turned over to the states. NCLB enabled each state to set its own standards, decide how it would assess achievement, and set its own calendar of adequate progress. With such flexibility, states were able to slow down the process. Therefore, the act was not as centralizing as the public believed, and when public support of the bill soured, voters blamed the federal government, not the states, for the policy's ineffectiveness. ${ }^{4}$ The federal government's new claim to authority in setting education policy is incomplete, and the federal government has pulled back from asserting it since 2001. Enforcement of NCLB has become more accomodating toward

\footnotetext{
${ }^{3}$ Author's conversation with Susan Neuman, President Bush's Assistant Secretary for Elementary and Secondary Education (2001-2003), October 2003.

${ }^{4}$ While an analysis of the relationship between incomplete authority migration and credit assignment is beyond the scope of this paper, it is intriguing to consider how governmental actors, in this case the states, may use the safeguards strategically not to block authority migration outright, but instead to cede just enough so that the other level of government appears responsible for poor outcomes.
} 
the states, and new initiatives, such as the Race to the Top, are based more on positive incentives and voluntary participation than the strict penalties set up under NCLB.

Constitutional reinterpretation ultimately involves the public, with changing public perception. When constitutional reinterpretation reaches the point of a broad consensus - such as the case with the recognition of the federal government's role in establishing racial equality and civil rights, for examplethen institutional safeguards (due to their own extrinsic motivations to please their constituents) will fall into line and uphold this new constitutional state.

The emergence of a public constitutional consensus is one of the more beautiful and vexing mysteries of constitutionalism. It is quite possible that the small debates that occur within and between safeguards as they consider the allowability of policy helps the public to form an opinion. It is also certainly that case that the fact that incremental change occurs builds experience with constitutional shifts; learning is fastest in practice, rather than through theoretical premise-making, and the public gains comfort and then expectation about constitutional order when it has positive experiences with shifts. When complementary institutions constrain constitutional dynamics to incremental change, the public can experience change and accept it long before it would have the chance to become codified.

When mitigated through the filters of the various safeguards, change is constrained to incremental alterations in interpretation. Change that moves too quickly - that varies too much from public conception of the federal 
balance - is nipped. Because of the safeguards' increasing ability to recognize and deter more major deviations from current constitutional custom, constitutional dynamics in the robust federation, one in possession of a system of complementary safeguards, is not a series of punctuated equilibria. Instead, it is a staccato flow of small progressions, much like the stuttering second hand of a swiss railway clock, pausing momentarily and then leaping ahead to catch up to the minute hand's advance.

With incremental change, not all change leads to immediate improvements. Recall the analogy of the policy innovator as a mountain climber who is dissatisfied with the present view. In the language of complex systems, the mountainscape may be changing over time, just as the nature of the problems that policies are designed to address changes. In some cases, when the policy landscape has changed, the policy innovation - the alteration to the federal boundaries - may bring immediate benefits to all. But in other cases the innovation is a step down the allegorical mountain; although the policy shift may bring immediate benefits to the policymaker, it may cause harm to other members of the federation. However, from the new vantage point, other policy changes may be available that weren't upon first review.

Even if transitions often require temporary downturns, It is important the the system not decline too much; for that we have selection mechanisms, some measure of the system's performance. In biology, the organism has a level of fitness; in finance, a corporation has a stock value. The performance of a nation-state may be measured in a number of ways, from its annual 
economic growth, to its infant mortality and expected lifespan statistics, to the duration of peace. In democratic systems, these indicators influence (but do not determine) the public's satisfaction with its government. Ultimately, in democratic federations, the selection mechanism is the public.

Another bonus of incremental change is that with localized small changes, where change approximates continuity, there is less chance that the change is irreversible. Experimentation gone awry can be corrected through reversion; there is less likelihood that path dependence creates disjunctures that cannot be undone. Rather than locking the union into permanent adjustments to the balance of authority as some of the literature on path dependence implies (David 1985, Arthur 1994), through reinterpretation of the past, or in our case, of constitutional clauses, paths are reversible (Bednar, Page, and Toole 2012). When complete change requires public reconception of the meaning of the constitution, it is easier to revert to similar meanings that to radically retool them.

The system of safeguards, when sufficiently complementary, enable incremental change. They respond to the federal or state government's attempts to push against the boundaries of federalism, but their imperfection creates a small window for policy experimentation. Unlike the standard models of compliance-maintenance mechanisms, these safeguards do not necessarily force system back into its initial state. Instead, they are flexible enough to allow the federation to slide into a new constitutional state. That is, the complementary safeguards of the robust federation are not equilibrium- 
reinforcing, but instead enable dynamic constitutional reinterpretation.

\section{Domain Linkages}

Up to this point I have described constitutional change as a permutation to the interpretation of a single clause, but constitutional change is not always confined to single policy domains. At times the change seems to diffuse throughout the text, affecting many clauses either simultaneously or sequentially, until the very nature of the federation has evolved. It is common to find references in the federalism literature, and to histories of federations writ large, that describe centralizing and peripheralizing eras. While the time boundaries of these periods may be subject to discussion, country specialists often agree with the broad characterization of changes in the distribution of power between the federal and state governments during these periods.

Neat periodization implies radical, exogenous constitutional reconstructions, but it is quite likely that constitutional change is mostly endogenous. Given the importance of public reconception, and that reconception often requires experience, radical shifts based on an inversion in ideas is unlikely. An alternative theory rejects periodization, arguing that shifts in the federal balance of authority result from an underlying and multidimensional process of continuous change. ${ }^{5}$ Theories of continuous change are promising. As they develop, care must be taken to avoid describing change as a linear process

\footnotetext{
${ }^{5}$ See Broschek 2010 for an overview of two historical-institutionalist models of continuous change with applications to the Canadian and German federations.
} 
with unchanging momentum. Complex systems theory would encourage us to think about a middle path: constitutional change is an ongoing process but subject to tips, moments of rapid acceleration. If the weight of authority alternately favors the federal government and then the states, the movement resembles a pendulum, swinging back and forth between the two extremes of centralization and decentralization. The pendulum slows, pauses, and reverses course at the extremes; its fastest speed comes during intermediate positions. These tips lend credence to the periodization tendency because eras do become recognizably distinct from those prior or subsequent, and yet do not rely on exogenous and sudden transformation.

Sometimes constitutional redirection begin with a single court case or piece of legislation. For example, many mark the New Deal legislation as the beginning of a period of centralization in the American federal system, and the Rehnquist Court (and particularly the United States $\mathrm{v}$ Lopez $^{6}$ ) decision as its end, and the start of a new "age of federalism" in the United States, where state influence is resurgent. The theory that I developed in sections ?? and ?? can help us to understand changes to single clauses - in this case, changes to the interpretation of the commerce clause. We now need a theory of how one change spreads into a full set, sufficient to lead to a new era in federal-state relations.

A common explanation for trends in peripheralization or centralization is that it results from a shift in the safeguards that preserve the federal bound-

\footnotetext{
${ }^{6}$ United States v Alfonso Lopez, Jr., 514 U.S. 549 (1995).
} 
aries, or changes in their influence relative to other safeguards (eg Riker 1964, Iaryczower et al 2001, Gibson and Falleti 2004, Bednar 2009). Scandals or personnel changes cause courts to lose legitimacy, or new parties take control, implementing new visions of the federal union, or the constitution is amended, changing one of the institutional safeguards directly. As an example of the latter instance, some argue that the Seventeenth Amendment to the U.S. Constitution, creating the direct election of U.S. Senators, permanently centralized the US federation by removing the key structural safeguard of state authority (e.g. Rossum 2001). On the other hand, Riker (1955) argues that the U.S. Senate should have kept the American federation fairly peripheralized, but the Senators never behaved as if they were beholden to the state legislatures, because the state legislatures failed to enforce their instructions. The seventeenth amendment only made permanent and formal what had long been true in practice: the Senate was an unreliable safeguard for the states.

If a model refers exclusively to institutional change then it cannot be complete. Each of these institutional safeguards ultimately depends upon public support for legitimacy and authority. If these institutions - say, the national executive - reinterpret the Constitution and redirects the nature of the federal union by promoting a set of programs that collects authority to the center, the public must support the change or it will not endure. Painstaking research by legal scholars reveals that even the judiciary cannot stray far from the public's views for long; a change as significant as a transformation of the 
nature of the union requires public acceptance (Dahl 1957, Funston 1975, Kramer 2004, Friedman 2009).

A change in the nature of the federal union, whether the states or the national government becomes more empowered relative to the other, is literally a system tip (Lamberson and Page 2012). In physical terms, the system transitions from one state to another. Complex systems can be highly interconnected, and during a transition, actions reverberate across the system broadly, and generate feedback, quickening and deepening the change in each area. System tips can produce large events. Examples of these sort of phenomena include market crashes, mass extinctions, and power grid failures.

These large events arise because of system connectivity. The parts of the system are integrated and interdependent. To carry the analysis over to our realm of interest - constitutional change in federations - it must be the case that legal and policy domains are not independent, but instead entwined. Constitutional eras imply trends across multiple policy domains. Change in one domain is not isolated, but instead triggers a change in another domain. In contrast with the hypothesis that constitutional shifts are created by institutional changes, here the source of the spread of constitutional reinterpretation is not solely a product of institutional change, but instead it is the change in one domain that serves as a catalyst for change in another domain. The theory of constitutional change needs to be able to explain how these distinct, apparently separable domains are related.

In a formal sense, constitutional domains are modular because they de- 
rive from independent clauses. Criminal law is not related to education law, for example. In practice, the policies in one domain may influence the development of policies in another, by introducing new perspectives or models of thought. The connection is often not found in ties between constitutional clauses, but in a paradigm shift in public perspective that leads to changes.

One example can be drawn from the civil rights era in the United States. In the 1950s and 1960s, racial equality gained public acceptance, spreading slowly from military desegregation, to the end of separate schools, ${ }^{7}$ to employment and public accommodations (Civil Rights Act of 1964), to changes to electoral laws (Voting Rights Act of 1965), and a transition in marriage law with the banning of antimiscegenation laws (the Loving case), ${ }^{8}$. Each of these policy transitions altered the federal-state relationship: either the Court overturned state legislation or, in the case of electoral law, the federal government stepped in to regulate policies constitutionally and traditionally left to the states. The nature of the federal union was altered during this era, expanding the federal government's reach in order to achieve social goals.

It is interesting to consider whether a single legal opinion or constitutional amendment could create a large event, a new constitutional era. One ready example comes from American constitutional history: the Dred Scott decision. ${ }^{9}$ In Dred Scott, the U.S. Supreme Court overturned an Act of Congress for only the second time in its history, and declared that people of African

\footnotetext{
${ }^{7}$ Brown v. Board of Education of Topeka, 347 U.S. 483 (1954).

${ }^{8}$ Loving v. Virginia, 388 U.S. 1 (1967).

${ }^{9}$ Dred Scott v. Sanford, 60 U.S. 393 (1857).
} 
descent cannot be citizens, despite the fact that in some northern states, Blacks could vote and hold public office. The decision rent the country in two, inflaming abolitionist sentiments in the North. While the Dred Scott decision was not the unique factor that doomed the states to civil war, it is symbolic of the country's phase transition by fomenting a movement that had been growing slowly prior to the Court's decision. With national nerves frayed by an accumulation of interstate and intergovernmental suspicion, the decision precipitated the nation from peace to war as the southern states resisted the northern domination and federal aggregation of power. It marked a turning point in American history.

When independent policies can be identified within an ideological or philosophical frame, they become connected in the public's eye. When a new policy alters the balance of power within the federation, perhaps by empowering the federal government, the public becomes more likely to accept policy centralization in policies connected within the ideological frame. Trends are created when the public views states' rights or federal intervention as a useful tool to further public goals. The public may even come to expect centralization of related policies despite adequate state policy alternatives.

At the microfoundational level, the spread of public expectations is explained by the theory of behavioral spillovers between games. Laws regulate governmental interactions, and agents-governments, or the policies that their citizens will tolerate-is a product of this regulatory environment. In response to a new problem, agents tend first to apply existing behaviors, 
and adapt them as necessary. The performance of any one institution is a product of the other institutions in the fuller institutional context. Notice that these spillovers are created by citizens applying what they know; and they are more likely to apply existing behaviors if they view the problems as similar.

A simple metaphor of a toolbox provides an intuition about how behavioral spillovers connect legal domains. Each citizen has a box filled with tools that she views as potential remedies for different policy problems. When a citizen encounters a problem to be solved, she can purchase a new tool, but she is more likely to root around in her toolbox to see if one that she already has might do the job. If she begins to see two problems as similar, and used a particular tool to solve one of the problems successfully, then she'll likely pick up that tool first to solve the second problem. Applying the metaphor to policy problems, one might think of two "tools" to respond to policy problems; let the state legislature work it out or let the federal government handle it. As the citizen's confidence in the federal government grows, for each new policy domain, she becomes more likely to approve of the federal government's intervention.

This behavioral process has been well established in laboratory settings applied to abstract problems (Bednar et al 2012). When subjects play two simple games simultaneously, they behave differently in each game than a control group of subjects who play each game in isolation. Behavior is context dependent. Although agents are free to treat each game independent of 
the other, agents' decisions are affected by the presence of another game. Agents tend to play similar strategies in each game, although they receive no additional rewards for doing so.

The model of multiple-game play is predictive, and simulation and experimental results confirm predictions. Response to institutions produces a measurable degree of variation, or entropy. In games that are easy to solvethat have a dominant strategy, or that otherwise require no coordination with others - agents quickly adopt the optimal strategy. In games that are more difficult to solve, particularly those that require coordination with an opponent (such as the repeated Prisoner's Dilemma) or where two actions produce similar payoffs (as in the Battle of the Sexes), agents take much longer to arrive at an optimal policy, and try many different strategies as they grope around for their best choice. Easy games, therefore, have low entropy, while more difficult games have higher entropy.

Using these measures of entropy for the games, a clear behavioral pattern emerges. When agents play multiple games simultaneously, they tend to solve the easier game first and then apply the same heuristic developed for the easy game to solve the more difficult game. While cognitive load is certainly a factor, the direction of behavioral spillovers runs from easier problems to harder problems: heuristics applied to solve the easier problem are far more likely to be used to solve the harder problem when agents play games simultaneously than when they play the harder game exclusively. When two problems are both difficult, if agents view them similarly, they tend to adopt 
similar strategies (Bednar et al 2012).

These predictive models may be informative to scholars of constitutional evolution. In some constitutional domains we may expect a small range of behavioral responses (diversity of policy) while in others, a broader range is likely. We'd expect little variation in areas of broadly settled law, or where there is little or no public disagreement over which level of government ought to control policy. When policy is controversial or the problem is new, we'd expect more public disagreement about which "tool" to apply: whether to grant the federal or state government authority. And to explain linkages, we would expect that the public would be most likely to accept the assignment of authority to either the federal or state government in a "difficult" policy domain if that same level of government had successfully solved a similar but less difficult problem.

Policy linkages are built around classifications of problem difficulty. Given the tendency first to solve easy problems (those that generate little political controversy), periods of centralization should begin with the federal government implementing policy in uncontested or uncontroversial domains, and then spreading to other domains as the public comes to expect the federal government's involvement. Another source of expanding authority comes as policy issues are reframed, newly tying them to existing federal authorities, as was the case with race linking together marriage law, education, and elections law. Once the federal government-and, perhaps more to the point, not the state governments, was accepted as the appropriate tool for end- 
ing racial discrimination in one domain, it became much easier to accept its involvement in other policies that could be tied to racial bias.

In domains with low entropy change remains possible: the consensus could be based upon the lack of controversy over the means and common agreement on the ends; if the policy environment changes, an innovation may be immediately recognized as a dominant solution and adopted broadly. Therefore it is possible that low entropy policy domains may be those with the fastest change, because adaptation is more quickly accepted by the public.

In sum, the theory of behavioral spillovers offers a possible roadmap for understanding the onset of centralizing or decentralizing eras. These complex systems results suggest that policy domains may be connected through the behaviors and expectations of the public. As policy becomes accepted practice in one domain, it becomes more likely that a similar intervention will be accepted in another domain. One can make some predictions about the kinds of policies that could start these tips: those where there is strong convergence of opinion or high demand for action are the conditions where we might expect the first experiments with a shift in power. If those initial experiments are successful, then further empowerment grows in probability in problem areas where there is high demand for a solution but no consensus over the method (i.e., in domains where the public lacks consensus about the appropriate level of government to intervene). While spillovers are likely to move from high-consensus domains to ones where the politics are more ambiguous, high consensus domains are not likely to be affected themselves. 
Therefore, if a transition in the federal system begins, the shift in eras is likely to manifest itself last in domains that are considered unproblematic and settled.

\section{Discussion}

This view of chaos in government is not one of despair. The system of American government flaunts virtually all tenets of legislative responsibility and administrative effectiveness. It appears always to be wasteful of manpower and money. At times it threatens the very democracy it is established to maintain. But it works, it works - and sometimes with beauty. (Grodzins 1966:7)

Grodzins referred to the messy - in his eyes chaotic - nature of the American federal system. On the surface, it does appear to be at least complex, if not chaotic. Federalism is a complex adaptive system, composed of systems of governance and rule enforcement, nested within systems. It operates on multiple spatial scales and its performance is influenced by the cultural and social system that guides the beliefs and behaviors of its residents. Effective change emerges from distributed, bottom-up experimentation; it is far less likely to originate through centralized engineering. Legal and policy do-

mains are linked through public perception, so that incremental change in one domain may spread.

It is the very complexity of the federal system that enables us to generate 
a theory of incremental constitutional change - of change to the constitution that does not involve amendment but instead is a reinterpretation of clauses so that the nature of federalism changes even as the words that create it remain the same. In the introduction I laid out three questions that an adequate theory of incremental constitutional change must address: (1) what is the source of innovation, (2) how is change constrained to be incremental, rather than punctuated, (3) how does change spread across legal and policy domains to become a full transition in the nature of the federal union, an era of centralization or decentralization?

A model of federalism, of the authority boundaries between federal and state governments, should engage how it is managed with a system of distinct, diverse agents. What it means to model federalism: to have a theory of how it is maintained as a system with distinct agents. As the paper argues, an equilibrium model can explain constitutional change primarily through exogenous forces. In this paper, I leverage results from complex systems theory to generate a preliminary theory of incremental, informal constitutional change to the boundaries of federalism.

In order to understand the development of any particular federation, or to theorize generally about federalism, one must adopt a systems-theory perspective. In doing so, one pays attention to systems characteristics such as openness, diversity, resilience, adaptability, and robustness. Grodzins, as systems theorist, had precisely the same intuition. With a few of federalism as a dynamical system, the distribution of authority is subject to continual 
renegotiation. This movement does not imply imbalance, and it certainly does not spell the end of the federation. To the contrary, it may be the best sign that the federal union is capable of beneficial adaptation.

To explain the source of constitutional innovation, the theory relies on the diversity of states and multiple institutions. With state diversity, diverse preferences lead to pushing against the existing boundaries of federalism in original ways. With several diverse institutions safeguarding that boundary, and each being imperfect and incomplete, some safeguards will permit policy experimentation, whether intentionally, because it accepts the constitutionality of the policy, or unintentionally, through institutional error. The diversity of agents leads to diversity of thresholds; means that the window remains open for exploration, if even only temporarily. Disagreements between safeguards (such as when legislation is approved by Congress but challenged by state governors or its constitutionality is challenged in court) helps to inform the public. Some safeguards engage the public only passively, as observers (court), while with others - elected officials, parties more broadly - the public is asked for its support. The public also forms an opinion about authority shifts as it gains experience with policy.

Informal constitutional change is constrained to be incremental when safeguards are complementary. While each safeguard is itself incomplete and imperfect, if they respond to different types of experimentation, from different sources, and have flaws that are independent (say, in the type of evidence that they consider), then safeguards grow increasingly likely to deter policy 
experimentation that pushes the boundaries of federalism too far, straining legal continuity.

And finally, complex systems can provide intuition about the spread of authority migration, so that authority accumulates, to the point where the nature of the federation has shifted to become either more centralized or decentralized. Policies are linked as citizens relate one to another through new ideological frames. These spillovers are most likely to flow from policy domains of high consensus to those that are more contentious or ambiguous. I have written this preface to a theory of constitutional change within the context of federal systems. While the essential elements of the thesis can be transposed to unitary systems to explain informal, incremental constitutional change, the diversity of agents and the multiplicity of interpretive possibilities makes federalism particularly well suited to change in constitutional meaning without change to the constitutional text. 


\section{References}

Arthur, Brian. 1994. Increasing Returns and Path Dependence in the Economy. Ann Arbor: University of Michigan Press.

Baker, Lynn A. 2001. "Conditional Federal Spending and States' Rights." Annals of the AAPSS 574 March 2001.

Balkin, Jack M. 2011. Constitutional Redemption: Political Faith in an Unjust World.

Bednar, Jenna. 2009. The Robust Federation: Principles of Design. Cambridge, UK: Cambridge University Press.

Bednar, Jenna. 2007. "Credit Assignment and Federal Encroachment." Supreme Court Economic Review 15:285-308.

Bednar, Jenna. 2006. "Is Full Compliance Possible? Conditions for Shirking with Imperfect Monitoring and Continuous Action Spaces." Journal of Theoretical Politics 18(3):345-373.

Bednar, Jenna, Yan Chen, Tracy Xiao Liu, and Scott E. Page. 2012. "Behavioral Spillovers and Cognitive Load in Multiple Games: An Experimental Study." Games and Economic Behavior 74(1):12-31.

Bednar, Jenna, Scott E. Page, and Jameson Toole. Forthcoming 2012. "Revised-Path Dependence." Political Analysis. 
Broschek, Jörg. 2010. "Federalism and Political Change: Canada and Germany in Historical-Institutionalist Perspective." Canadian Journal of Political Science 43(1):1-24.

Dahl, Robert A. 1957. "Decision-Making in a Democracy: The Supreme Court as a National Policy-Maker." Journal of Public Law 6:279-95.

David, Paul. 1985. "Clio and the Economics of QWERTY." American Economic Review 75(2):332-337, Papers and Proceedings of the NinetySeventh Annual Meeting of the American Economic Association.

Easton, David. 1957. "An Approach to the Analysis of Political Systems." World Politics 9(3):383-400.

Elkins, Zachary, Tom Ginsburg, and James Melton. 2009. The Endurance of National Constituitons. New York: Cambridge University Press.

Eskridge, William N., Jr., and John Ferejohn. 2010. A Republic of Statutes: The New American Constitution. New Haven, CT: Yale University Press.

Fisher, R.A. 1930. The Genetical Theory of Natural Selection. Oxford: Clarendon Press.

Friedman, Barry. 2003. "Mediated Popular Constitutionalism." Michigan Law Review 101(8):2596-2636. 
Friedman, Barry. 2009. The Will of the People: How Public Opinion Has Influenced the Supreme Court and Shaped the Meaning of the Constitution. New York: Farrar, Straus and Giroux.

Funston, Richard. 1975. "The Supreme Court and Critical Elections." American Political Science Review 69(3):795-811.

Gibson, Edward L. and Tulia G. Falleti. 2004. "Unity by the Stick" in Federalism and Democracy in Latin America, Edward L. Gibson, ed. Baltimore: Johns Hopkins University Press.

Grodzins, Morton. 1966. The American System: A New View of Government in the United States. Chicago: Rand McNally \& Company.

Herzog, Don. 2000. "Externalities and Other Parasites." University of Chicago Law Review 67(3):895-923.

Iaryczower, Matias, Sebastian Saiegh, Mariano Tommasi. 2001. "Coming Together: The Industrial Organization of Federalism." New York University manuscript.

Inman, Robert P. and Daniel L. Rubinfeld. 1997. "Rethinking Federalism." Journal of Economic Perspectives 11(4):43-64.

Kincaid, John. 1994. "Foreword: The New Federalism Context of the New Judicial Federalism." Rutgers Law Journal 26: 913-948. 
Koppelman, Andrew. 2012. "Respect and Contempt in Constitutional Law, or, is Jack Balkin Heartbreaking?" Maryland Law Review 71:PAGES.

Kramer, Larry D. 2004. The People Themselves: Popular Constitutionalism and Judicial Review. New York: Oxford University Press.

Lamberson, PJ and Scott E. Page. 2012. "Tipping Points." Forthcoming, Quarterly Journal of Political Science.

March, James G. 1991. "Exploration and Exploitation in Organizational Learning." Organization Science 2(1):71-87.

Michelman, Frank I. 2003. "Ida's Way: Constructing the Respect-Worthy Governmental System." Fordham Law Review 72:345.

Page, Scott E. 2010. Diversity and Complexity. Princeton, NJ: Princeton University Press.

Page, Scott E. 2007. The Difference: How the Power of Diversity Creates Better Groups, Firms, Schools, and Societies. Princeton, NJ: Princeton University Press.

Post, Robert C. 2003. "Fashioning the Legal Constitution: Culture, Courts, and Law." Harvard Law Review 117(1):4-112.

Riker, William H. 1955. "The Senate and American Federalism." American Political Science Review 49(2):452-469. 
Rossum, Ralph A. 2001. Federalism, the Supreme Court, and the Seventeenth Amendment: The Irony of Constitutional Democracy. New York: Lexington Books.

Thayer, James B. 1893. "The Origin and Scope of the American Doctrine of Constitutional Law." Harvard Law Review 7(3):129-156.

Tsebelis, George. 2002. Veto Players: How Political Institutions Work. Princeton, NJ: Princeton University Press.

Whittington, Keith E. 1999. Constitutional Construction: Divided Powers and Constitutional Meaning. Cambridge, MA: Harvard University Press. 